\title{
Dossiê A Constituição de 1988 e a Crise Democrática
}

\section{Os distintos olhares para as instituições}

As três últimas décadas testemunharam um claro afastamento entre a Ciência Política e a História. As razões são diversas. Contribuem, por um lado, as mudanças na universidade e no sistema de pós-graduação, responsáveis por um progressivo processo de institucionalização e profissionalização, nos quais a especialização e o crescimento vertiginoso das publicações sobre cada área do conhecimento tornam o trabalho com diversas disciplinas cada vez mais difícil, ao menos do ponto de vista do sistema de produtividade vigente. Há, todavia, motivos de outra sorte, fundados em certos pressupostos teóricos e epistêmicos que foram se tornando hegemônicos na Ciência Política do pós-1989.

No que se refere à produção da Ciência Política no Brasil, faz-se necessário destacar que a guinada neoinstitucionalista tem alguma das suas raízes na fundação, em fins da década de 1960, de cursos de pós-graduação na Universidade Federal de Minas Gerais (UFMG) e no Instituto Universitário de Pesquisas do Rio de Janeiro (IUPERJ). Ao mesmo tempo em que alguns autores recuperavam a produção intelectual anterior, enquadrada como o que frequentemente classificavam como pensamento ou imaginação político-social brasileira ${ }^{1}$, ganhou força a ideia de certa especificidade plena do conhecimento político, que por aí ofereceria explicações mais científicas do que as formuladas até então (FORJAZ, 1997; LESSA, 2011).

O crescente descrédito de explicações "estruturais" contribui para a normalização de conceitos de política que frequentemente se identificam à ação, vista como caminho para uma "autonomia da política" perante explicações sociológicas e históricas. Eloquente neste sentido é o prefácio de Fernando Limongi, um dos mais influentes cientistas políticos brasileiros, ao livro Poliarquia, de Robert Dahl2:

"A constituição desse objeto de pesquisa - a transição de regimes - foi concomitante à afirmação da autonomia explicativa de variáveis propriamente políticas. Dito de outra maneira, essa literatura foi um dos veículos por meio dos quais a ciência política liberou-se da teoria da modernização e de suas explicações calcadas no processo histórico de transformação das estruturas sociais. Em explicações desse tipo, regimes políticos independem da intervenção dos atores políticos e das escolhas institucionais que fazem. Não há lugar para a política." (LIMONGI, 2005, p. 12)

Desponta dessa perspectiva um conceito de Ciência Política em franca oposição às explicações sociológicas ou históricas, vistas como reducionistas por menosprezarem a dimensão propriamente política dos fenômenos. Se a política pode ser objeto dos mais diversos campos de estudo, haveria, contudo, um objeto específico para a ciência da política: as instituições políticas e sua influência sobre as ações dos atores. São inegáveis os vínculos dessa perspectiva com a revolução behaviorista, transcorrida nos anos 1950 nos Estados Unidos, e seus posteriores desdobramentos em teorias da escolha racional e do neoinstitucionalismo ${ }^{3}$. Contra a perspectiva da sistematicidade e a excessiva valorização dos trabalhos teóricos e do discurso, se 
impõe a defesa de uma disciplina orientada por casos empíricos, de preferência possíveis de serem analisados por técnicas quantitativas de pesquisa, e arredia a assumir as grandes narrativas e pressupostos subjacentes a seus trabalhos. São evidentes, nesse movimento, as marcas da guinada teórica da microeconomia na década de 1950 na Ciência Política, inclusive por meio do compartilhamento dos mesmos pais fundadores, como Kenneth Arrow, James Buchanan, Mancur Olson e Anthony Downs. Tais tipos de trabalho, já realizados na década de 1970, se popularizaram na academia brasileira por meio dos estudos das transições de regimes autoritários para democráticos, a chamada "transitologia" (VITULLO, 2001), e posteriormente, através de estudos das feições institucionais da Constituição de 1988, tornaram-se o paradigma hegemônico no estudo das instituições políticas ${ }^{4}$.

Há evidentes contribuições do campo. Muitas dessas pesquisas, cujo inventário ultrapassa os objetivos desse texto, avançaram na compreensão da ordem constitucional de 1988, sobretudo no que se refere às dinâmicas intraparlamentares, quase sempre subvalorizadas em pesquisas anteriores. A bibliografia também foi particularmente importante para a consolidação de uma narrativa política sobre a efetividade e estabilidade institucional da Constituição (CHALOUB, LYNCH, 2018), contra as interpretações majoritárias de latino-americanistas, como Scott Mainwaring (1991, 1993) e Barry Ames (2003), que defendiam a insustentabilidade do sistema político da carta de 1988 por seu esforço de conjugar o presidencialismo, marcado por uma lógica majoritária, com perspectivas descentralizadoras e proporcionais típicas da lógica consensual (LIJPHART, 2003), como um sistema eleitoral proporcional para o legislativo, com a exceção do Senado, e um Estado federativo. A literatura neoinstitucionalista também contribuiu para a compreensão do novo arranjo federativo do estado brasileiro que produziu inovações em relação às políticas públicas, e especialmente, às políticas sociais (MENICUCCI, 2003; BICHIR, 2010). Trabalhos desse perfil foram, ainda, contrapontos aos argumentos conservadores críticos à Constituição ${ }^{5}$, contemporâneos à própria constituinte e presentes ao longo de toda a sua trajetória.

Em tempos de forte debate em torno de alguns dos seus principais conceitos explicativos, como o de "presidencialismo de coalizão", é necessária uma mais ampla reflexão acerca dos seus pressupostos. Cunhado por Sérgio Abranches (1986) e reformulado em alguns aspectos, como o papel do regimento do Congresso Nacional e das lideranças, por Argelina Figueiredo e Fernando Limongi (2000), o conceito buscava expor a dinâmica de funcionamento da instituições política posteriores à Constituição de 1988, que conseguiria, por tal lógica e em dissonância com boa parte da bibliografia internacional, produzir governabilidade.

Uma consequência da hegemonia desse paradigma é o predomínio de certa presunção de contemporaneidade dos objetos políticos. Mesmo os trabalhos marcados pela perspectiva do institucionalismo histórico( PIERSON, SKOCPOL, 2002), minoritários ante o neoinstitucionalismo da escolha racional, mas por vezes mobilizados, frequentemente atribuem às reconstruções históricas uma feição de préhistória do presente, de modo que a historicidade tenderia a se esgotar na estabilidade dos modelos vigentes no pós-1988. Os vaticínios sobre o eficaz funcionamento das instituições frequentemente produziram diagnósticos sobre uma forte ruptura com o passado, com a construção de um paradigma da continuidade. Até as mudanças são usualmente tratadas como variações do mesmo tema. 
A crise posterior a 2013 colocou em xeque a capacidade explicativa de tais teorias. Após uma gentil despedida pela porta principal, o passado retornou pelas janelas e passou a marcar o debate público nacional, ganhando feições mais contemporâneas do que em um passado próximo. Os debates sobre o presente passaram a ser atravessados, mais do que usualmente, pelas disputas em torno de narrativas históricas. Não se trata apenas de um fenômeno brasileiro.

Em 2014, Paulo Arantes recorreu ao par conceitual horizonte de expectativas e espaço de experiência, de Reinhart Koselleck, para diagnosticar certa ruptura com o conceito moderno de história, marcado pela ideia de progresso e por um futuro aberto às inovações. $\mathrm{O}$ fechamento do horizonte de expectativas, que teria se fundido com o espaço de experiência, produziria uma época de "expectativas decrescentes", na qual a ruptura entre o passado e o presente, consequência de uma ideia forte de progresso seria esmaecida ${ }^{6}$. Como consequência desse fenômeno, o passado teria se tornado "contemporâneo" e passado a marcar os debates contemporâneos.

Cícero Araújo (2014) parte das ideias de Arantes para interpretar a centralidade do golpe de 1964 em seu cinquentenário. Segundo o autor, o golpe pareceria mais contemporâneo em 2014 do que nas efemérides anteriores, quando as promessas da redemocratização soavam mais promissoras. Se as disputas sobre a história estão presentes em todas as conjunturas, Arantes e Araújo argumentam que elas seriam ainda mais centrais no cenário brasileiro. O protagonismo no debate público de atores e discursos favoráveis ao golpe militar de 1964, e à ditadura ali instalada, assim como o seu enorme sucesso eleitoral em 2018 expõem a precisão dos diagnósticos dos dois autores. A disputas em torno da história se tornam incontornáveis para compreender 0 Brasil das primeiras décadas do século XXI.

Sabe-se que a Constituição de 1988 finca raízes em continuidades e descontinuidades da história recente brasileira e que, na contemporaneidade, é atravessada por tais movimentos. Se a mobilização dos atores sociais e políticos em torno da nova carta foi real, concreta e paradigmática na história política brasileira, a manutenção do que à época era chamado de "entulho autoritário" nos indica a força dos discursos e da ação política de atores autoritários durante a Assembleia Nacional Constituinte e nas críticas que surgiram após a promulgação da Carta de 1988.

A Constituição é um tema privilegiado para melhor compreender esses movimentos. Como aponta livro recente no qual tomamos parte (PERLATTO, DULCI, CHALOUB, 2020), as disputas da atual crise democrática têm nas narrativas sobre a Constituição de 1988 um elemento central. Se as críticas à carta de 1988 nunca cessaram, desde a Constituinte até as inúmeras reformas no texto constitucional, há nos últimos anos um claro recrudescimento dessas críticas, tanto no seu volume quanto na sua radicalidade.

Tais discursos não apenas contestam no presente a viabilidade da Constituição, que seria responsável por boa parte das nossas atuais mazelas, como conjugam histórias alternativas no futuro do pretérito. $O$ ataque às dimensões republicanas, democratas e aos institutos social-democratas da Constituição são um dos pontos de convergência interna dos diversos grupos da heterogênea coalização bolsonarista, unida em sua representação de 1988 como um momento de vitória das esquerdas.

Em torno da recusa ao público, despontam contestações radicais que propõe ordens baseadas no indivíduo, caso das várias narrativas neoliberais; na família, como nos discursos neoconservadores; ou do líder de feições militarescas, marca dos discursos reacionários ou da linguagem fascista (CHALOUB, 2020). O mote central das 
críticas neoliberais é que a Constituição "não cabe no orçamento". Haveria, segundo este discurso, um irrealismo no suposto excesso de promessas e direitos da Constituição, que estariam em descompasso com a ciência das ações individuais diante de recursos escassos: a economia. O discurso da desagregação moral, por sua vez, também argumenta em torno de um "excesso de direitos', mas para apontar a excessiva intervenção de um Estado corrupto como razão da perda da centralidade da família e da imposição de lógicas estranhas à sociedade, que seria naturalmente conservadora. Após a eleição de Bolsonaro, começou a ser tornar frequente um terceiro discurso, de tintas abertamente fascistas, que opõe a abstração da Constituição à concretude da decisão do líder. Nenhuma frase expõe melhor essa perspectiva do que a afirmação, de abril do último ano: "Eu sou a Constituição". Cada uma dessas narrativas aponta para um futuro do pretérito diverso, que transcorreria normalmente caso os setores progressistas não tivessem sido supostamente hegemônicos na Constituinte? .

Em um cenário de acentuada crise, as narrativas históricas em torno de 1988 se tornaram elementos incontornáveis das disputas políticas do presente. Sem desconsiderar a relevância de uma análise neoinstitucionalista da Constituição, é fundamental refletir sobre os caminhos que construíram tal institucionalidade e os sentidos diversos atribuídos aos processos pelos diversos atores, pois é evidente que a Constituição, como todas, não é um documento imutável e fechado em si, mas um terreno de disputa política, marcado pelas flutuações de sentido que são marca desse tipo de embate.

Tal movimento torna-se particularmente acentuada no caso brasileiro pela opção, de clara feição social-democrata (CITTADINO, 1998), de constitucionalizar boa parte das políticas sociais (COUTO, ARANTES, 2006). A questão não se esgota, todavia, nas feições institucionais da carta. Devem ser consideradas também uma longa duração de marcas da nossa sociabilidade, como o que Wanderley Guilherme dos Santos chama de " hobbesianismo social pré-participatório e estatofóbico" (SANTOS, 1993), e padrões intelectuais, que podem qualificar os debates sobre uma longa tradição nacional autoritária.

\section{Os textos}

O presente dossiê se estrutura a partir do pressuposto de que, na atual conjuntura, refletir sobre as instituições a partir de um olhar que não nega sua historicidade é um modo de não apenas expor as tensões no atual debate público, como de refletir sobre a permanência de diversas questões ao longo das mais de três décadas de vida da Constituição.

Para tanto, foram selecionados, por meio de pareceristas, tanto artigos que refletissem sobre o momento constituinte, ressaltando os diversos projetos e visões de mundo em disputa, quanto trabalhos que apontassem para a Constituição como eixo dos conflitos políticos posteriores, de modo a expor como as disputas em torno dos sentidos e interpretações da Constituição são um modo de reconstruir as histórias do país das últimas décadas e de melhor compreender as disputas do presente.

Além da presente apresentação, o dossiê é composto por oito artigos, uma resenha e uma entrevista inédita. Segue uma breve apresentação de todos. 
O dossiê se inicia com uma entrevista com o deputado federal José Genoíno. A escolha do deputado Genoíno decorreu não apenas da sua atuação na Constituinte, mas também dos momentos anteriores e posteriores ao evento. $\mathrm{O}$ principal objetivo da entrevista é oferecer ao leitor do dossiê um outro tipo de discurso sobre a Constituinte, que trouxesse a memória de um partícipe e protagonista desse processo. Mais do que um caminho para acessar um passado distante, a memória desponta como meio para compreender seu constante processo de atualizações e reelaborações das ideias e disputas políticas.

Pedro Rolo Benetti recupera as propostas derrotadas nos debates da constituinte de 1987-88 sobre a organização das forças repressivas do Estado com o intuito de demonstrar as ações e reconstruir as disputas determinantes para a continuidade de ideias e institutos vigentes na Ditadura Militar. Com isso, o artigo pretende não apenas retomar os debates do passado, mas levantar questões para a crise do modelo atual.

Karen Artur e Ligia Barros de Freitas, por sua vez, analisam a disputa em torna da constitucionalização do direito do trabalho a partir de análises da Assembleia Nacional Constituinte, de recentes ações judiciais no Supremo Tribunal Federal e do Grupo de Altos Estudos do Trabalho (GAET), instituído pelo governo de Jair Messias Bolsonaro. O objetivo do artigo é analisar os distintos lugares e formulações do pensamento "liberal-conservador" nesses momentos.

Na sequência, Lucas Nascimento Ferraz Costa analisa as atas e diários das comissões de subcomissões da Assembleia Nacional Constituinte para refletir sobre a atuação dos lobbies e grupos de interesse na área da saúde. Sua hipótese geral é que a capacidade de "centralização de interesses", ou seja, a "capacidade de agregar interesses comuns em um único bloco coeso" é o principal fator explicativo para a possibilidade de influência dos lobbies.

O quarto artigo do dossiê, de Mariele Troiano, investiga o papel do Legislativo no projeto democrático da Constituição de 1988 a partir das comissões e das audiências públicas. Para tanto, a autora realiza uma análise de conteúdo das atas da Assembleia Nacional Constituinte. Sua principal hipótese aponta para a centralidade do Legislativo nesse projeto democrático brasileiro, sobretudo em razão da sua permeabilidade às demandas da sociedade civil.

Logo depois, Viviane Magno Ribeiro pretende "recuperar a discussão sobre a participação popular no processo constituinte daquela época", a partir da Filosofia Política e do poder constituinte, bem como através do " modo pelo qual o período da transição política foi experimentado por diferentes atores sociais". Assim, a autora almeja rediscutir os caminhos que levaram a produção de uma carta constitucional progressista e refletir sobre os sentidos da Constituição à época e hoje.

Josué Medeiros, por sua vez, relaciona a crise da democracia brasileira aos ataques à Constituição de 1988 e à disputa que sempre marcou o texto constitucional. Ele busca reconstruir tal vínculo a partir das relações entre a atuação do Partido dos Trabalhadores no processo constituinte e a posterior constituição do que ele conceitua como "lulismo", "com seus sentidos gerais e seus impasses", sobretudo em relação às Jornadas de Junho de 2013.

O artigo de Eric Nogueira de Andrade reconstrói a trajetória do conceito "presidencialismo de coalizão", "examina em que medida ele se conecta com a temática da reforma e crise institucional" e analisa quatro momentos históricos em que 
o Congresso brasileiro colocou em votação inúmeras propostas de reforma. Seu objetivo é compreender a relação entre as narrativas teóricas sobre a Constituição e seus momentos de crise.

No último artigo, Argemiro Cardoso Moreira Martins e Larissa Caetano Mizutani buscam investigar inovações no processo constituinte de 1988, que teriam colocado em questão algumas concepções estabelecidas sobre os conceitos de poder constituinte e povo. A partir dos Anais da Assembleia Nacional Constituinte de 19871988 e de dados oficiais da Câmara dos Deputados e do Senado Federal do Brasil, eles refletem sobre a "relação entre representante político e representado", que teria se rearranjado a partir da participação popular experimentada na Constituinte.

Por fim, Giselle Braga Bastos resenha a nova edição da obra "A gramática política no Brasil: Clientelismo e insulamento burocrático", de Edson Nunes, com ênfase em sua longeva influência no debate acadêmico brasileiro, sobretudo em torno de temas como o "clientelismo", ao longo das últimas décadas.

A expectativa dos organizadores é que o dossiê contribua para explicitar os lugares da Constituição de 1988 no debate político contemporâneo, de modo a não apenas refletir sobre os vínculos entre suas interpretações e a atual crise, como a apontar possíveis caminhos para novas pesquisas e perspectivas.

\section{Notas}

1. As referências são os trabalhos de Wanderley Guilherme dos Santos, disponíveis em SANTOS (2017) em e Bolivar Lamounier (1982).

2. Deve-se ressaltar que Limongi constrói uma interpretação de Dahl que reforça o papel das instituições em sua obra e diz mais sobre o projeto intelectual do brasileiro do que da inserção do norteamericano no cenário intelectual da Ciência Política das últimas décadas.

3. Para uma boa avaliação crítica dessas perspectivas, ver CARVALHO, 2009.

4. Para uma análise aprofundada desse movimento teórico na Ciência Política, ver LESSA, 2011.

5. A coletânea organizada por Paulo Mercadante, Constituição de 1988: o avanço do retrocesso (1990), que contou com capítulos de intelectuais conservadores como Miguel Reale e Ives Gandra Martins, é um bom exemplo desse discurso.

6. Outros autores localizam a ruptura com essa ideia de progresso no pós-guerra, como é o caso de Gumbrecht (2014).

7. Esses argumentos são desenvolvidos de forma mais detida em Chaloub, 2020.

\section{Referências bibliográficas}


ABRANCHES, Sérgio. 1988. Presidencialismo de coalizão: o dilema institucional brasileiro. In: DADOS. Rio de Janeiro, v. 31, p. 5-34.

AMES, Barry. 2003. Os entraves da democracia no Brasil. Rio de Janeiro: FGV.

ARANTES, Paulo. 2014. O Novo Tempo do Mundo. São Paulo: Boitempo.

ARAÚJO, Cícero. Política, História e a questão da atualidade do Golpe de 1964. 2014. In: NAPOLITANO, C. J. et al. O Golpe de 1964 e a Ditadura Militar em Perspectiva. São Paulo: Editora Cultura Acadêmica.

BICHIR, Renata Mirandola. 2010. O Bolsa Família na berlinda? Os desafios atuais dos programas de transferência de renda. Novos estudos CEBRAP , n.87, pp.115-129.

CITTADINNO, Gisele. 1998. Pluralismo, direito e justiça distributiva. Rio de Janeiro: Lumen Juris.

CHALOUB, Jorge. Crítica e crise: A banalidade do golpe no Brasil contemporâneo. Insight Inteligência, v. 90, p. $140-154,2020$.

CHALOUB, J. G. S.; LYNCH, C. E. C., 2018. O pensamento político-constitucional da República de 1988: um balanço preliminar (1988-2017). In: HOLLANDA, Cristina Buarque; VEIGA, Luciana Fernandes; AMARAL, Oswaldo E. (Org.). A Constituição de 1988: trinta anos depois. Curitiba: Editora UFPR, v. 1, p. 251-280.

COUTO, Cláudio Gonçalves; ARANTES, Rogério Bastos. 2006. Constituição, governo e democracia no Brasil. Revista Brasileira de Ciências Sociais, 21 (61), p. 41-62.

FORJAZ, M. C. S. 1997. "A emergência da ciência política no Brasil: aspectos institucionais". Revista Brasileira de Ciências Sociais, vol. 12, nº 35.

LAMOUNIER, Bolívar. 1982. A ciência política no Brasil: roteiro para um balanço crítico. In: A ciência política nos anos 80. Brasília: Editora da UnB. pp. 407-433

LESSA, Renato. 2011. Da interpretação à ciência: por uma história filosófica do conhecimento político no Brasil. Lua Nova [online]. n.82, pp.17-60.

LIMONGI, Fernando. Prefácio. In: DAHL, Robert. Poliarquia: participação e oposição. São Paulo: Unesp, 2005.

LIMONGI, Fernando; FIGUEIREDO, Argelina. Bases institucionais do presidencialismo de coalizão. Lua Nova, p. 81-106, São Paulo, 1998. 
LIJPHART, Arend. 2003. Modelos de Democracia: Desempenho e Padrões de Governo em 36 Países. São Paulo, Civilização Brasileira.

MAINWARING, Scott. 1991. Politicians, parties and electoral systems: Brazil in a comparative perspective. Comparative Politics, 24 I.

Democracia presidencialista multipartidária: o caso do Brasil. 1993. Lua Nova, São Paulo.

MENICUCCI, TMG. 2003. Público e privado na política de assistência à saúde no Brasil: atores, processos e trajetória [Tese de Doutorado]. Belo Horizonte: Faculdade de Filosofia e Ciências Humanas, Universidade Federal de Minas Gerais.

PERLATTO, Fernando (Org.) ; DULCI, João (Org.), CHALOUB, Jorge (Org.), 2020. . A Nova República em crise. 1. ed. Curitiba: Appris.

SANTOS, Wanderley Guilherme. 1993 Razões da Desordem. Rio de Janeiro, Rocco.

SKOCPOL, T.; PIERSON P. 2002. Historical Institutionalism in Contemporary Political Science. In: KATZNELSON I; MILNER. HV Political Science: State of the Discipline. New York: W.W. Norton. pp. 693721.

VITULLO, Gabriel E. 2001.Transitologia, consolidologia e democracia na América Latina: uma revisão crítica. Revista. Sociologia Política 2001, n.17, pp.53-60. ${ }^{8}$ 